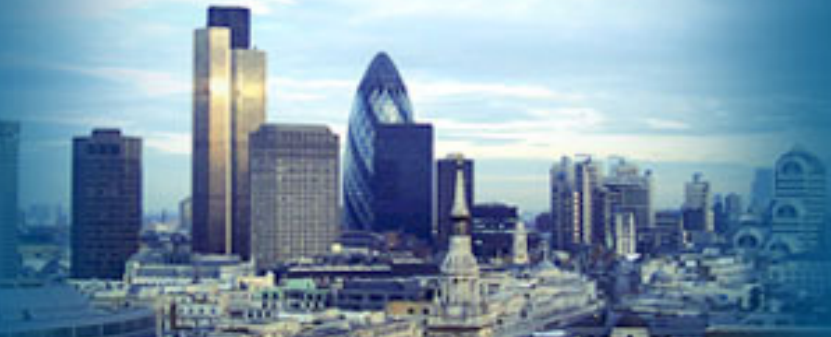

LONDON metropolitan university

CENTRE FOR EMEA BANKING, FINANCE \& ECONOMICS

\author{
Structural Breaks, Rural Transformation and \\ Total Factor Productivity Growth in China
}

Kefei You

Nicholas Sarantis

Working Paper Series

No 35/12 


\title{
Structural Breaks, Rural Transformation and \\ Total Factor Productivity Growth in China
}

\author{
Kefei You* \\ Centre for EMEA Banking, Finance and Economics, \\ London Metropolitan University, UK \\ Nicholas Sarantis \\ Cass Business School, City University London, UK
}

\begin{abstract}
This paper carries out an empirical investigation into the contribution of rural transformation, which can produce efficiency gains over and above those associated with technical progress, to total factor productivity in China during the post-reform period 1980-2010. For the first time for China, the roles of rural transformation and technical progress are examined whilst structural breaks are taken into account. We employ Bai and Perron (1998, 2003a, b) methods which allow for multiple structural breaks at unknown dates and can be applied for both pure and partial structural changes. We also evaluate the robustness of our results by employing alternative production functions and two capital series. Two structural breaks near the Tiananmen Square incident in 1989 and the implementation of further reforms and opening-up measures in 1995 were identified for both capital series. We found the contribution of rural transformation to total factor productivity to be significant and positive across all regimes. However, its importance to the growth of total factor productivity has been declining over time, while that of technical progress has been increasing.
\end{abstract}

Keywords: Structural breaks; Rural transformation; Total factor productivity; China

JEL classification: 030, 047, 053

Acknowledgement: We would like to thank Fung Kwan, Wei Chi, Xiaoye Qian and Xiaobo Zhang for their comments on an earlier version of the paper presented at the Chinese Economists Society 2008 Macao Conference, University of Macau. The opinions expressed in the paper and any remaining errors are our responsibility. We are thankful to Professor Bai and Ms Zhenjie Qian for sending us data of real capital stock for 1952-2005. We are also grateful to two anonymous referees for their constructive comments and suggestions. As usual, the opinions expressed in the paper and any remaining errors remain our responsibility.

*Corresponding author: London Metropolitan University, 84 Moorgate, London, EC2M 6SQ, UK. Tel: +44 (0)20 7320 1520, Fax: +44 (0)20 7320 1585, E-mail: k.you@londonmet.ac.uk. 


\section{Introduction}

A few studies have highlighted the efficiency gains in the post-reform period resulting from the reallocation of labor across sectors in China. For instance, World Bank (1996) finds that during 19851994, the movement of labor from agriculture to industry and, to a lesser extent, services contributed about one percentage point to aggregate GDP growth. More recently, Brandt, Hsieh and Zhu (2008) employ data during 1978-2004 and also find the contribution of labor reallocation from agriculture to non-agriculture is about one percentage point to output growth. Bosworth and Collins (2008) divide the post-reform period into two sub-periods 1978-1993 and 1994-2004 and find labor reallocation out of the agricultural sector accounts for, respectively, 1.7 and 1.2 percentage points of aggregate GDP growth. As argued by Woo (1998), movement of labor between sectors (away from agriculture to other sectors) increases aggregate output when the marginal product of labor in the agricultural sector is lower than that in the industrial and services sectors.

However, these studies are based on growth accounting rather than on an econometric investigation. More crucially, none of the above papers or other studies on China's productivity take structural breaks into account. There have been major economic and political changes in China in the past few decades ${ }^{1}$. Ignoring structural breaks could lead to inaccurate inferences about China's productivity growth. In order to investigate the possibility of multiple structural changes, we employ the Bai and Perron (1998, 2003a, b) stochastic multiple structural break model which tests for the presence of multiple structural breaks occurring at unknown dates and provides an estimate of the break points. It also has the flexibility of allowing for partial structural breaks, where only some of the coefficients are allowed to change over time, as well as pure structural breaks, where all coefficients are allowed to change over time.

\footnotetext{
${ }^{1}$ See Section 5 for a detailed discussion.
} 
Furthermore, most studies that investigate China's productivity growth employ only the Cobb-Douglas production function, which assumes unit elasticity of substitution and constant returns to scale ${ }^{2}$. In this paper we also examine the role of rural transformation under two alternative production functions, i.e. Constant Elasticity of Substitution (CES) and Variable Elasticity of Substitution (VES) functions, which allow these two restrictions to be relaxed in order to investigate whether the role of rural transformation remains robust.

We employ two alternative capital series to evaluate whether the results are sensitive to the choice of capital measurement ${ }^{3}$. The two capital series are extended from Chow and Li (2002) and Bai et al. (2006a). To our knowledge, it is the first time the capital series of Bai et al (2006a) is used to estimate production functions for China.

The paper is organised as follows: Section 2 specifies the Cobb-Douglas production function that incorporates rural transformation. Section 3 explains the structural break test. Section 4 discusses measurement of variables and data sources. Section 5 reports the estimates of break dates and estimates of the Cobb-Douglas production function. Section 6 applies the break dates to CES and VES production functions. Section 7 presents the estimates of total and net factor productivity and discusses the contribution of rural transformation to total factor productivity. Section 8 compares our findings with previous studies. Section 9 sets out our conclusions.

\section{The Production Function}

Following Chow and $\mathrm{Li}$ (2002), the Cobb-Douglas production function is written as

$$
y=A k^{\alpha}=e^{\beta t} k^{\alpha} ;
$$

\footnotetext{
${ }^{2}$ To our knowledge, existing studies examining alternative forms of production functions for China are not at aggregate level (e.g. Jia, 1991; Bairam, 1999; Xu, 1999) or include China in a large panel (e.g. Duffy and Papaggeorgiou, 2000; Karagiannis et al, 2004).

${ }^{3}$ It is interesting to note that all previous studies have used only one capital series.
} 
where $y$ and $k$ denote real output per labor and real capital stock per labor respectively, $A$ measures total factor productivity (TFP), $\beta$ measures the effect of technical progress, and $\alpha$ is the capital share of income.

China's transformation from a central-planned to a market-oriented economy is characterized by "rural transformation", which covers both rural-urban migration and rural industrialization transformation"4. The former refers to the internal labor migration from countryside to cities (Zhao, 1999a, b; Zhang and Song, 2003). The latter refers to the establishment of rural enterprises (e.g. Town and Village Enterprises (TVEs)) which attracts farmers out of the field (Wang 1999; Zhu, 2000). Both result in shifts of labor from a low productivity agricultural sector to more productive industrial and services sectors. Therefore, even if the levels of technology in different sectors remain unchanged, labor flows from sectors with lower marginal productivity of labor to sectors with higher marginal productivity of labor will increase the TFP. In other words, it is not only the size of labor that matters for output growth; the distribution of labor also plays an important role.

\footnotetext{
4 In 1980, employees in urban and rural areas accounted for $24.8 \%$ and $75.2 \%$ of total employees in China respectively. During the post-reform period, continuous rural-urban migration has led to huge changes. By 2010, the number of employees in urban areas had jumped to $45.6 \%$ of total employees while the number of employees in rural areas had fallen to 54.4\%. Furthermore, the composition of employees working in rural areas has also altered dramatically. Prior to 1978, there were no alternative types of employment for farmers (apart from working on the farm). But during the post-reform period, rural industrialisation mainly in the form of establishing Town and Village Enterprises (TVEs) has given farmers the opportunity to work outside the farm without leaving their families. In 2010, TVEs employed $38.4 \%$ of rural employees. There has also been a dramatic movement of labor between sectors. In 1980, 68.7\% of employees were in the agricultural sector. In contrast, the agricultural sector accounted for only $36.7 \%$ of employees in 2010 while secondary and tertiary sectors accounted for $63.3 \%$ of employees.
} 
Therefore, in this paper we break down TFP into net factor productivity (NFP) and rural transformation $(R T)$. NFP captures the pure technical progress and $R T$ captures the efficiency gains resulted from rural transformation. Hence the production function takes the following form:

$$
y=T F P k^{\alpha}=(N F P)\left(R T^{\gamma}\right) k^{\alpha}=\left(e^{\beta t}\right)\left(R T^{\gamma}\right) k^{\alpha}
$$

where $\gamma$ measures the effect of $R T$ on $T F P$.

Taking logarithms of equation (2) yields the following equation which is used in the econometric estimations in Section 5:

$$
\ln y_{t}=c+\alpha \ln k_{t}+\beta t+\gamma \ln (R T)_{t}+u_{t}
$$

\section{Structural Break Test - Bai and Perron (1998, 2003a, b)}

As emphasized earlier, China's economy has been subjected to major political and economic policy changes in the past few decades. In order to identify these structural changes, we use the multiple structural break model of Bai and Perron (1998, 2003a, b) (BP hereafter). They consider the following multiple linear regression with $m$ breaks:

$$
y_{t}=x_{t}^{\prime} \beta+z_{t}^{\prime} \delta_{j}+u_{t} \quad t=T_{j-1}+1, \ldots, T_{j}
$$

for $j=1, \ldots, m+1$. In this model, $y_{t}$ is the dependent variable; $x_{t}(p \times 1)$ and $z_{t}(q \times 1)$ are vectors of covariates and $\beta$ and $\delta_{j}$ are corresponding vectors of coefficients; $u_{t}$ is the error term. The break points $\left(T_{1}, \ldots, T_{m}\right)$ are treated as unknown and conventionally $T_{0}=0$ and $T_{m+1}=T$. As $\beta$ is not subject 
to structural change whilst $\delta_{j}$ is, this model is a pure structural break model when $p=0$ and a partial structural break model when otherwise.

Regarding the method of estimation, the following objective function is employed

$$
\left(\hat{T}_{1}, \ldots, \hat{T}_{m}\right)=\arg \min _{T_{1}, \ldots, T_{m}} S_{T}\left(T_{1}, \ldots, T_{m}\right)
$$

where the sum of the squared residuals

$$
S_{T}\left(T_{1}, \ldots, T_{m}\right)=\sum_{i=1}^{m+1} \sum_{T_{i-1}+1}^{T_{i}}\left(y_{t}-x_{t}^{\prime} \beta-z_{t}^{\prime} \delta_{j}\right)^{2}
$$

The break points estimators $\left(\hat{T}_{1}, \ldots, \hat{T}_{m}\right)$ are obtained such that the objective function is minimized. As the minimization is taken over all partitions $\left(T_{1}, \ldots, T_{m}\right)$ (note that $T_{i}-T_{i-1} \geq q$ ), the break point estimators are global minimizers of the objective function and the coefficients estimators $\hat{\beta}$ and $\hat{\delta}_{j}$ are ones associated with the $m$ - partition $\left\{\hat{T}_{j}\right\}$.

In order to choose the number of breaks, BP first consider the F-statistics ( $\operatorname{Sup} F_{T}(k)$ test) to test the null of no structural breaks $(m=0)$ against the alternative that there are breaks $(m=k)$. They then consider the double maximum ( $U D$ max and $W D \max$ ) tests, both testing the null of no structural break against an unknown number of breaks given some upper bound $M$. $U D \max =\max _{1 \leq m \leq M} \operatorname{SupF}_{T}(m)$ and $W D$ max attaches different weights to the individual $\mathrm{F}$ tests so that the marginal $p$-values are equal across values of $m$. BP also provide a third set of tests, the $\operatorname{SupF}_{T}(l+1 \mid l)$ test, which rejects in favour of a $(l+1)$ breaks model if the overall minimal value of the sum of squared residuals is sufficiently smaller than the sum of squared residuals from the $l$ break model. 
The BP method has some flexible features. First, it can consider autocorrelation and heteroscedasticity in the residuals. Second, it allows for different moment matrices for the regressors in different regimes. To allow for all these features, we adopt the most general BP specification ${ }^{5}$.

With regard the procedure for identifying the number and location of break points, BP suggest an initial examination of the $U D \max$ or $W D \max$ tests to see if at least one break is present. If there is, then the number of breaks can be decided based on the $\operatorname{SupF}_{T}(l+1 \mid l)$ statistics, selecting $m$ such that the tests $\operatorname{SupF}_{T}(l+1 \mid l)$ are insignificant for $l \geq m$. Critical values for all tests are provided by Bai and Perron (1998, 2003b, c).

\section{Variable Measurement and Data Source}

Due to the Chinese government's long-standing policy of restricting migration from rural to urban areas, rural transformation did not become a national phenomenon until the implementation of reform and opening-up policy in the late 1970s (Zhao, 1998). We therefore estimated the Cobb Douglas production function for the period 1980-2010. To evaluate the robustness of the results to the choice of the capital series, we employ two real capital stock series. The first capital series, $K 1$, is the extended series of Chow and Li (2002). The second capital series, K2, is the extended series of Bai et al (2006a). The other series include real GDP $(Y)$, labor $(L)$ and rural transformation $(R T)$. All data are described in detail in the Appendix B. K1, $K 2$ and $Y$ are divided by labor and denoted by $k 1, k 2$ and $y$ respectively. Time trend $t$ starts from 1980.

\footnotetext{
${ }^{5}$ To be more specific, following the notation of Bai and Perron (2003a), we consider the most general BP specification, i.e. cor_u $u=1$, het_z $z=1$. Trimming is set at $\varepsilon=0.20$, higher than the conventional 0.15 used by most structural break studies employing the BP methods as Bai and Perron (2003a) recommend a higher value of trimming when these flexible features are allowed. Correspondingly, we have $m=3$, i.e. a maximum of 3 breaks is allowed. GAUSS program used in BP is available from Pierre Perron's home page at http://people.bu.edu/perron.
} 


\section{Empirical Results}

We use the partial structural break model to estimate equation (3). Specifically, the constant and the coefficient for the capital labor ratio are fixed for the whole sample period and coefficients for the time trend and rural transformation are allowed to vary across different regimes ${ }^{6}$. The results are presented in Table 1.

For both capital labor ratios $k 1$ and $k 2$, the structural break test has identified two significant breaks in 1989 and 1995, thus dividing the whole sample period into three regimes: 1980-1989, 1990-1995 and 1996-2010.

After 1978, the central government's priority shifted from political "class struggle" to "economic development". Major reforms including agriculture reform, fiscal decentralization and opening up the economy were carried out and, following these reforms, economic growth resumed (Qian, 2000). However, in the late 1980s, high economic growth resulted in high inflation. Hence an austerity program was put into place to cool down the over-heated economy. The Tiananmen Square incident in 1989, a political campaign demanding deeper and faster reform policies, was suppressed. Following this incident, the conservatives who promoted recentralization gained ground in the central government. In 1989, China experienced the slowest economic growth rate of $4.1 \%$ in the whole of the 1980 s.

After the early 1990s, centralization was resisted by local government and many previous reform measures still went ahead. In particular, in 1992, Deng Xiaoping's southern tour firmly promoted economic reconstruction and a more market-oriented approach to boosting the Chinese economy (Zhou, 1993). As a result, high economic growth returned. However, by the mid-1990s, the economic system as a whole was still at a half-way stage between a planned and a market economy. Reforms after

\footnotetext{
${ }^{6}$ During the initial estimation, the coefficient on the capital labor ratio and the constant were also allowed to vary, but the statistics suggested there was no structural break.
} 
the mid-1990s were shifted towards establishing market-supporting institutions (e.g. formal fiscal federalism, a centralized monetary system, and a social safety net), a rule-based market system to create a level playing field, and privatization and restructuring State-Owned Enterprises (SOEs) (Qian, 2000). Furthermore, a new exchange rate system (unification of the official and swap rates) was introduced in 1994, which had significant implications for China's international competitiveness and export performance. We identified a break in 1995, in accordance with the division of the different stages of reforms discussed above.

The capital shares $(\alpha), 0.1652$ using $k 1$ and 0.2045 using $k 2$, are highly significant but much lower than reported in Chow and Li (2002), 0.5577, where the same capital series of $k 1$ is used for 1952-1998 (excluding 1958-1969). This implies that the inclusion of $R T$ in the production function reduces capital share since rural transformation captures the part of the change in TFP that was previously ignored As indicated by Hu and Khan (1997), although capital accumulation is important, sustained growth in total factor productivity, which includes rural transformation in our study, is the driving force behind China's economic boom.

The coefficients for the time trend $t$ are all positive and highly significant, indicating positive technical progress growth in all regimes. Compared with Chow and Li (2002), who reported a technical progress growth rate of $3.03 \%$ for $1978-1998$, we observe higher growth rates of technical progress across all regimes for both capital series when two structural breaks are accounted for. It is interesting to note that the impact of technical progress on production has been higher over the last sixteen years than it was in the 1980s.

We found positive and highly significant coefficients for $R T$ across all regimes for both capital series. It further confirms our expectation that rural transformation is an important contributor to China's 
economic growth period ${ }^{7}$. An important observation is that the effect of rural transformation on production declined during the last sixteen years by comparison with that during the 1980s. This pattern is opposite to that which we have found for technical progress. Such a reversed pattern of coefficients reflects the fact that rural transformation and technical progress are two competing components of total factor productivity. It should also be noted that since the middle 1990 s there has been faster growth in investment in education, skilling and research and development following president Jiang Zemin's statement that China's continuing economic development would become more dependent on scientific and technical progress and on improved labor quality (Tisdell, 2009).

It is worth pointing out that results using capital labor ratios $k 1$ and $k 2$ are highly consistent, except that the coefficients of $R T$ are moderately lower in the case of $k 2$, which could be explained by a slightly higher estimate of capital share compared with using $k 1$.

\section{Alternative Production Functions}

The Cobb-Douglas production function assumes unit elasticity of substitution and constant returns to scale. In this section we further investigate the contribution of rural transformation within the framework of CES and VES specifications, where these restrictions can be relaxed. The sample period is

\footnotetext{
${ }^{7}$ Following World Bank (1996) and Brandt et al (2008), we also investigated the contribution of another form of labor reallocation, namely ownership transformation, in the Cobb-Douglas production function. Ownership transformation refers to labor reallocation out of State Owned Enterprises (SOEs) to non-SOEs and is measured as the ratio of SOE employees to urban employees. However, BP methods suggested no breaks for both $k 1$ and $k 2$ when ownership transformation is included, which was rather counter-intuitive, and more importantly, the OLS estimates for the whole sample period (without structural breaks) showed that ownership transformation was insignificant and when it was included, time trend also became insignificant. Therefore, in contrast to World Bank (1996) and Brandt et al (2008), we did not find that ownership transformation contributed to China's productivity growth. For an explanation for why ownership transformation may not contribute to productivity growth, please refer to Bai et al (2006b).
} 
1980-2010. We apply the same break dates identified in Section $5^{8}$, i.e. 1989 and 1995 for both $K 1$ and $K 2$, to CES (equation 7) and VES (equations 8) production functions ${ }^{9}$.

$$
\begin{gathered}
\ln Y=c+\beta t+\gamma \ln R T-(\varphi / \rho) \ln \left(\delta K^{-\rho}+(1-\delta) L^{-\rho}\right) \\
\ln Y=c+\beta t+\gamma \ln R T+\varphi \theta \ln K+\varphi(1-\theta) \ln (L+\eta \theta K)
\end{gathered}
$$

The results are reported in Table 2 and Table 3 for CES and VES production function, respectively. In all equations, the coefficients for $R T$ are highly significant and positive in all regimes for both $K 1$ and $K 2$. Furthermore, their values display the same pattern as in the CobbDouglas production function. These findings confirm the important role played by rural transformation in total factor productivity growth in China throughout our sample period, irrespective of the production function and capital series employed.

The coefficients for time trend are positive in all regimes and their values also display the same pattern as in the Cobb-Douglas production function. However, in contrast to $R T$, they are insignificant in the first regimes in all cases and also insignificant in the third regimes in the two alternative functions using $K 2$.

Wald tests for the returns to scale parameter, $\varphi$, show that the null hypothesis of constant return to scale, i.e. $\varphi=1$, cannot be rejected in all cases. In addition, Wald tests suggest that the null of unit elasticity of substitution, i.e. $\rho=0$ for the CES specification and $\eta=0$ for VES specification cannot be rejected in all cases. These results imply that the aggregate CES and VES production functions collapse to

\footnotetext{
${ }^{8}$ To our knowledge, the structural break test for nonlinear models is rather limited and may not be applicable to the specific cases of CES and VES production functions. For instance, Kapetanios (2002) proposes testing for structural breaks in nonlinear dynamic models using artificial neural network approximations. But the methods do not allow for partial structural change and the neural network is specified using the radial basis function and logistic function. In addition, we expect break dates to be the same irrespective of econometric methods used to detect them. Therefore, we applied the break dates obtained using the BP methods in the previous section to CES and VES specifications.

${ }^{9}$ Please refer to Appendix A for a brief introduction to CES and VES specifications and the derivations of equations (7) and (8). Both production functions were estimated by non-linear least squares.
} 
the Cobb Douglas function. Therefore, we conclude that no evidence in favour of CES or VES over CobbDouglas production function is found.

\section{Productivity}

Based on the coefficients of the Cobb Douglas production function shown in Table 1, the growth rates of total factor productivity (GTFP), net factor productivity (GNFP), and productivity due to rural transformation (GCRT) are calculated and reported in Table $4^{10}$. The growth rates are further depicted in Figures 1-3 respectively. Again, results obtained for productivity growth using $k 1$ and $k 2$ are highly consistent.

Table 4 shows that during 1980-1989, 1990-1995 and 1996-2010, the average growth rates of CRT are $2.14 \%, 2.40 \%$ and $1.32 \%$ respectively when using $k 1 ; 1.64 \%, 1.71 \%$ and $1.05 \%$ respectively when using k2. It is interesting to notice that the highest growth rate of CRT occurred during the 1990-1995 period, despite the lowest estimates of the coefficient on $R T$ for this period. This can be explained by the average annual growth rate of $R T$ during the same period being $3.05 \%$, the highest in all three regimes. On one hand, after the short disruption of the Tiananmen Square incident in 1989, TVEs revived and continued to absorb large amount of rural labor. Compared with 1989, the number of employees in TVEs increased by around 30 percent (from 93.7 million to 128.6 million) in 1995. Regarding the number of employees, TVEs have surpassed SOEs and became the largest employer in China since 1993. On the

\footnotetext{
${ }^{10}$ Levels are calculated as: $N F P 1_{t}=\ln y_{t}-\hat{\alpha} \ln k 1_{t}-\hat{\gamma}_{j} \ln (R T)_{t} ; T F P 1_{t}=\ln y_{t}-\hat{\alpha} \ln k 1_{t} ; C R T 1_{t}=T F P 1_{t}-N F P 1_{t}$; where $j=1, \ldots, m+1$, and $\mathrm{m}$ is the number of breaks and $C R T$ denotes productivity contributed by rural transformation. Note levels are in natural logarithms. Therefore, growth rates are calculated as the first difference of the natural logarithms. Same applies when $k 2$ is used. Due to space constraint, we do not report levels in this paper. But interestingly we observe an upwards trend in the levels of TFP1, TFP2 NFP1 and NFP2 throughout our sample period. Regarding the levels of CRT1 and CRT2, they show a small increase during the third regime (1995-2010) in comparison to the 1980s and a slight decline during the second regime (1990-1995) in accordance with the pattern of coefficient estimates on $R T$.
} 
other hand, the establishment of Special Economic Zones and other coastal cities since late 1980s and early 1990s attracted large amounts of foreign direct investment (FDI). The FDI was mostly channeled to export oriented enterprises, which have been the destinations of thousands of internal migrants from rural to urban areas. In addition, the development of other forms of enterprise has also absorbed a large amount of labor from rural areas. For instance, self-employed and private enterprises in rural areas accounted for 35.3 million employees in 1995, equivalent to about a third of the number of employees in SOEs. All three factors have led to the fastest growth in $R T$ during the second regime.

For the three corresponding regimes, the average growth rates of NFP are $3.58 \%, 6.57 \%$ and $5.50 \%$ respectively when using $k 1 ; 3.60 \%, 6.93 \%$ and $4.85 \%$ respectively when using $k 2$. Therefore, there is an interesting contrast between the average growth rates of CRT and NFP: CRT has been lower during the last fifteen years (1996-2010) than it was during 1980-1995, whilst NFP displays the opposite pattern. This shows that in the long run, NFP seems to be a more sustainable source of TFP growth compared with $R T$. This contrast is further demonstrated in Figures 1 and 2. We also observe significant slowdown in all growth rates in 2008 due to the global financial crisis, though the growth rates for TFP and NFP picked up again in 2010.

Looking at the shares, we found that $R T$ continues to make a significant but declining contribution to TFP growth over time. Specifically, when the capital labor ratio $k 1$ is used, rural transformation accounts for 37.4\%, $26.8 \%$ and $19.4 \%$ of TFP growth during 1980-1989, 1990-1995 and 1996-2010 respectively. When the capital labor ratio $k 2$ is used, the corresponding ratios are $31.3 \%, 19.8 \%$ and $17.7 \%$. In contrast, the shares of NFP display an increasing trend irrespective of the capital series used. In particular, in the last fifteen years, the growth rate of NFP has accounted for over $80 \%$ of the growth rate of TFP. This implies that despite the importance of rural transformation, technical progress has become the main drive behind the growth of total factor productivity. Therefore, our empirical findings seem to indicate that 
the Chinese economy is moving towards a more sustainable pattern of growth, relying more and more on technological development.

\section{Comparative Analysis}

We compare our findings with those reported in previous literature in Tables 6 and $7^{11}$. Most previous studies calculate productivity growth using pre-specified capital shares (e.g. World Bank, 1996; Hu and Khan, 1997; Maddison, 1998; Woo, 1998; Bosworth and Collins, 2008; Brandt et al, 2008) ${ }^{12}$. In our study, all parameters are estimated, including the one for capital share. Capital series $K 1$ is extended from Chow and Li (2002), but our estimations report a much lower capital share than Chow and Li (2002) when contribution made by rural transformation to TFP is taken into account. Capital share when we use $K 2$ is slightly higher than that of $K 1$ but still much lower than Chow (1993) and Chow and Li (2002).

The contribution of rural transformation using $K 1$ is the highest $(2.14 \%$ in $1980-1989,2.40 \%$ in 1990-1995 and 1.32\% in 1996-2010) compared with previous studies (e.g. World Bank, 1996; Woo, 1998; Bosworth and Collins, 2008; Brandt et al, 2008). The same is true when using K2, except that it is slightly lower than Bosworth and Collins $(2008)^{13}$. Irrespective of the capital series used, TFP growth rates using $K 1$ are higher than those reported by all previous studies which ignore the role of rural transformation (e.g. Chow and Li, 2002; Borensztein and Ostry,

\footnotetext{
${ }^{11}$ It is important to note that none of the existing studies uses data for the recent period 2005-2010. The vast majority of these papers use samples that end in the middle 1990s. Only Bosworth and Collins (2008) and Brandt et al (92008) extend their samples up to 2004. Therefore these comparisons should be treated with caution.

12 Different capital series has been used in previous studies. For instance, capital stock data of Woo (1998), Maddison (1998) and Borensztein and Ostry (1996) is based on Li (1992), World Bank (1996) is based on Nehur and Dhareshwar (1993) and Bosworth and Collins (2008) is based on Hsueh and Li (1999), all with updating for recent years; whilst Hu and Khan (1997) and Brandt et al (2008) construct their own capital stock series.

${ }_{13}$ Bosworth and Collins (2008) study productivity growth of China and India. The sample period 1978-2004 was divided into 1978-1993 and 1994-2004 as after 1993 is India's post-reform era. They then apply growth accounting to both sub-periods to obtain productivity growth rates.
} 
1996; Hu and Khan, 1997; Maddison, 1998). Compared with studies that account for the role of rural transformation, TFP growth rates using $K 1$ are higher than World Bank (1996) and Woo (1998) but lower than Bosworth and Collins (2008) and Brandt et al (2008) in some regimes. The same pattern is observed when using $K 2$.

All studies mentioned above are based on given capital shares and growth accounting methods (except Chow (1993) and Chow and Li (2002)), and none of them have examined the role of rural transformation when structural breaks are taken into account. We therefore believe that our results are more reliable.

\section{Conclusions}

This paper carries out an empirical investigation into the contribution of rural transformation, which can produce efficiency gains over and above those associated with technical progress, to total factor productivity in China during 1980-2010. For the first time for China, the roles of rural transformation and technical progress in productivity growth are examined by taking structural breaks into account. We employ the Bai and Perron (1998, 2003a, b) methods which allow us to test for multiple structural breaks at unknown dates. We also evaluate the robustness of our results by employing alternative production functions and two capital series.

The structural break test identified two significant breaks; one in 1989, when the Tiananmen Square incident occurred, and the other in 1995, when further institutional reforms and opening up policies were implemented. The break dates are identical irrespective of the capital series employed. We found that both rural transformation and technical progress have a positive and significant effect on production across all regimes. More importantly, we found that rural transformation remains a significant contributor to total factor productivity and output growth in 
China irrespective of the production function and capital series employed, even when we allow for different regimes. However, despite its importance, the contribution of rural transformation to total factor productivity growth has been declining over the sample period, whilst that of technical progress has been increasing. This evidence seems to indicate that the Chinese economy is moving towards a pattern of growth that relies increasingly on technological development. Therefore, if China is to maintain its high economic growth even when the tap of rural transformation as a growth engine is closed, high and continuous investment in education and research and development will be essential. 


\section{Appendix A. CES and VES Production Functions with Rural Transformation}

The CES production function assumes varied returns to scale and an elasticity of substitution different from unity. Following Brown and De Cani (1963), CES production function takes the form:

$$
Y=A\left[\delta K^{-\rho}+(1-\delta) L^{-\rho}\right]^{-\varphi / \rho}
$$

where $\rho$ is the substitution parameter that determines the elasticity of substitution $\sigma . \delta$ is the distribution parameter; for any given value of $\sigma$ (or $\rho$ ), $\delta$ determines the functional distribution of income. $\varphi$ is the returns to scale parameter. The elasticity of substitution $(\sigma)$ is given by $\sigma=1 /(1+\rho)$. When $\varphi=1$ and $\rho=0$, equation (A1) collapses to the Cobb-Douglas production function.

In contrast to CES production function, the VES production function assumes that the elasticity of substitution is a linear function of capital over labor ratio (Revankar, 1971). We consider the following VES production function:

$$
Y=A K^{\theta \varphi}[L+\eta \theta K]^{(1-\theta) \varphi}
$$

where $\varphi$ is the returns to scale parameter. Both $\theta$ and $\eta$ determine the capital share and the labor share of income. The elasticity of substitution is derived as $\sigma=1+\eta(K / L)$. Hence $\sigma$ varies linearly with the capital-labor ratio around unity. If $\varphi=1$ and $\eta=0$, equation (A2) collapses to the CobbDouglas production function.

Similar to equation (2), we decompose total factor productivity into net factor productivity and rural transformation for equations (A1) and (A2), and then by taking natural logarithms we obtain equations (7) and (8) respectively: 


$$
\ln Y=c+\beta t+\gamma \ln R T-(\varphi / \rho) \ln \left(\delta K^{-\rho}+(1-\delta) L^{-\rho}\right)
$$

$$
\ln Y=c+\beta t+\gamma \ln R T+\varphi \theta \ln K+\varphi(1-\theta) \ln (L+\eta \theta K)
$$




\section{Appendix B. Data Sources and Variable Measurement}

The main data sources are China Statistical Yearbook (CSY) 2011 of China National Statistical Bureau, Chow and Li (2002) and Bai et al (2006a). Sample period is 1980-2010 ${ }^{14}$.

1. Real GDP of China (Y): it is constructed by adjusting nominal GDP using GDP deflator. Data of nominal GDP is collected from CSY 2011. The GDP Deflator is calculated using the same methodology as Jun $(2003)^{15}$

2. Total Number of Employed Persons (L): data is collected from CSY 2011.

3. Rural Transformation (RT) (\%): it is defined as the ratio of employed persons by non-agricultural sectors (which include industrial and services sectors) to total number of employed persons. A higher percentage implies a higher level of rural transformation, i.e. proportionally fewer farmers work in the field. Data of the employed persons by industrial and service sectors is collected from CSY 2011.

4. Real Capital Stock (K1): it is obtained by extending the real capital series of Chow and Li (2002) from 1952-1998 to 1952-2010 using same methods. Details of the methods can be found at Chow and Li (2002) and hence are not repeated here. Data needed for our extension include real GDP, GDP deflator, real consumption, real net export and depreciation. Data for nominal net exports and nominal consumption are from CSY 2011 and these are adjusted by the GDP deflator and Consumer Price Index (obtained from CSY 2011) respectively to obtain the real values. Total depreciation is the sum of provincial depreciation, data of which is from various issues of CSY.

\footnotetext{
${ }^{14}$ Although the reform and opening up policy was announced in 1978, it took a couple of years for these policies to be fully implemented. Therefore, we start our sample period from 1980. As Chow and Li (2002) and Bai et al (2006a) both use 1978 as the base year for the capital stock series, we also use 1978 as our base year to obtain the consistency.

${ }^{15}$ World Development Indicators (WDI) 2011 provides GDP for China (current local currency unit), which is consistent with the nominal GDP data of CSY 2011.
} 
5. Real Capital Stock (K2): it is obtained by extending the real capital series of Bai et al (2006a) from 1952-2005 to 1952-2010 using same methods. For detailed explanation of these methods, please refer to Bai et al (2006a). Data needed for our extension include investment in construction and installation, investment in equipment and instruments, price index of investment in construction and installation and price index of investment in equipment and instruments. All data are collected from CSY 2011. 


\section{References}

Bai, C.-E., Hsieh, C.-T. and Qian, Y., 2006a, "The Return to Capital in China", Brookings Papers on Economic Activity 2:2006.

Bai, C-E., Lu, J. and Tao, Z., 2006b, The Multitask Theory of State Enterprise Reform: Empirical Evidence from China, The American Economic Review, 96, No. 2, 353-357.

Bai, J. and Perron, P., 1998, "Estimating and Testing Linear Models with Multiple Structural Changes", Econometrica, 66, 47-68.

Bai, J. and Perron, P., 2003a, "Computation and Analysis of Multiple Structural Change Models", Journal of Applied Econometrics, 18, 1-22,

Bai, J. and Perron, P., 2003b, "Critical Values in Multiple Structural Change Tests", Econometrics Journal, $6,72-78$.

Bai, J. and Perron, P., 2003c, "Critical Values for Multiple Structural Change Tests (Unpublished Tables)", unpublished manuscript.

Bairam, E. I., 1999, "Domestic versus Foreign Capital and Returns to Scale in China's Provincial Industries", Applied Economics Letters, 6, 621-24.

Borensztein, E. and Ostry, J. D., 1996, "Accounting for China's Growth Performance", American Economic Review, 86, 225-8.

Bosworth, B. and Collins, S. M., 2008, "Accounting for Growth: Comparing China and India", Journal of Economic Perspectives, 22(1), 45-66. 
Brandt, L., Hsieh, C.-T., and Zhu, X., 2008, "Growth and Structural Transformation in China”, in Brandt, L. and Rawski, T. G., Eds., China's Great Economic Transformation, Cambridge University Press.

Brown, M. and De Cani, J., 1963, "Technological Change and the Distribution of Income", International Economic Review, 4(3), 289-309.

Chow, G., 1993, "Capital Formation and Economic Growth in China", Quarterly Journal of Economics, $108,809-42$.

Chow, G. and Li, K.-W., 2002, "China's Economic Growth: 1952-2010", Economic Development and Cultural Change, 51, October, 247-56.

Duffy, J., and Papageorgiou, C., 2000, "A Cross-Country Empirical Investigation of the Aggregate Production Function Specification," Journal of Economic Growth, 5(1), 87-120.

Hsueh, T. and Li, Q., Eds., 1999, China's National Income, 1952-1995, Boulder, CO:

Westview.

Hu, Z. F. and Khan. M. S., 1997, "Why is China Growing So Fast?", IMF Staff Papers, 44, 103-31.

Jia, L., 1991, "A Quantitative Analysis of Chinese Industrial Structure and Technological Change: Production Functions for Aggregate Industry, Sectoral Industries and Small Scale Industry", Applied Economics, 23, 1733-40.

Jun, Z., 2003, "Investment, Investment Efficiency and Economic Growth in China", Journal of Asia Economics, 14, 713-734. 
Kapetanios, G., 2002, Testing for Structural Breaks in Nonlinear Dynamic Models Using Artificial Neural Network Approximations", Working Paper No. 470, Department of Economics, Queen Mary, University of London.

Karagiannis, G., Palivos, T., and Papageorgiou, C., 2004, "Variable Elasticity of Substitution and Economic Growth: Theory and Evidence", in Diebolt, C. and Kyrtsou, C., Eds., New Trends in Macroeconomics, Springer Berlin Heidelberg.

Li, J., 1992, "Productivity and China's Economic Growth", The Economic Studies Quarterly, 43(4).

Maddison, A., 1998, Chinese Economic Performance in the Long-run, Paris: OECD Development Centre Studies.

Nehru, V. and Dhareshwar, A., 1993. "A New Database on Physical Capital Stock: Sources, Methodology and Results", Revista de Analisis Economica, 8(1), 37-59.

Newey, W. and West, K., 1987, "A Simple Positive Semi-Definite, Heteroskedastic and Autocorrelation Consistent Covariance Matrix", Econometrica, 55(3), 703-8.

Qian, Y., 2000, "The Process of China's Market Transition (1978-98): The Evolutionary, Historical and Comparative Perspectives (1978-98)", Journal of Institutional and Theoretical Economics, 156(1), 15171.

Revankar, N. S., 1971, "A Class of Variable Elasticity of Substitution Production Functions", Econometrica, 39(1), 61-71.

Tisdell, C., 2009, "Economic Reform and Openness in China: China's Development Policies in the Last 30 Years", Economic Analysis and Policy, Queensland University of Technology, School of Economics and Finance, 39(2), 271-94. 
Wang, D., 1999, "Socioeconomic Characteristics of Rural Urbanization in Southern Jiangsu, China", International Journal of Social Economics, 26 (1/2/3), 290-7.

Woo, W. T., 1998, "Chinese Economic Growth: Sources and Prospects", in M. Fouquin and F. Lemoine Eds., The Chinese Economy, Paris: Economica, London

World Bank, 1996, The Chinese Economy: Fighting Inflation, Deepening Reform, A World Bank Country Study, Washington, D.C.: the World Bank.

Xu, Y., 1999, "Agricultural Productivity in China", China Economic Review, 10, 108-21.

Zhang, H., and Song, S., 2003, "Rural-Urban Migration and Urbanization in China: Evidence from TimeSeries and Cross-Section Analyses", China Economic Review, 14, 386-400.

Zhao, Y., 1999a, "Labor Migration and Earnings Differences: The Case of Rural China", Economic Development and Cultural Change, 47(4), 767-82.

Zhao, Y., 1999b, "Leaving the Countryside: Rural-to-Urban Migration Decision in China", American Economic Review, 89(2), 281-6.

Zhou, S., 1993, "Deng Xiaoping's Southern Tour: Elite Politics in Post Tiananmen China", Asian Survey, $33,739-56$.

Zhu, Y., 2000, "In Situ Urbanization in Rural China: Case Studies from Fujian Province", Development and Cultural Change, 31, 413-34. 
Table 1. Structural Break Tests and Parameter Estimates of the Cobb-Douglas

\section{Production Function}

\begin{tabular}{|c|c|c|c|c|c|}
\hline \multicolumn{3}{|c|}{ Capital labor ratio $k 1$} & \multicolumn{3}{|c|}{ Capital labor ratio $k 2$} \\
\hline \multicolumn{3}{|c|}{ Tests } & \multicolumn{3}{|c|}{ Tests } \\
\hline$U D \max ^{\mathrm{a}}$ & \multicolumn{2}{|l|}{$W D \max (1 \%)^{\mathrm{b}}$} & $U D \max$ & \multicolumn{2}{|l|}{$W D \max (1 \%)$} \\
\hline $633.26 * * *$ & \multicolumn{2}{|l|}{$836.13^{* * *}$} & $299.57^{* * *}$ & \multicolumn{2}{|l|}{$499.40 * * *$} \\
\hline $\operatorname{Sup}_{T}(1 \mid 0)^{\mathrm{c}}$ & $\operatorname{SupF}_{T}(2 \mid 1)^{\mathrm{d}}$ & $\operatorname{SupF}_{T}(3 \mid 2)^{\mathrm{e}}$ & $\operatorname{SupF}_{T}(1 \mid 0)$ & $\operatorname{SupF}_{T}(2 \mid 1)$ & $\operatorname{SupF}_{T}(3 \mid 2)$ \\
\hline \multirow[t]{3}{*}{$14.86^{* *}$} & $33.63 * * *$ & 0.10 & 0.97 & $70.76^{* * *}$ & 0.00 \\
\hline & \multicolumn{2}{|l|}{ Breakpoint(s) } & \multicolumn{3}{|c|}{ Breakpoint(s) } \\
\hline & \multicolumn{2}{|l|}{19891995} & \multicolumn{3}{|c|}{19891995} \\
\hline Regime 1 & Regime 2 & Regime 3 & Regime 1 & Regime 2 & Regime 3 \\
\hline 1980-1989 & 1990-1995 & $1996-2010$ & 1980-1989 & 1990-1995 & $1996-2010$ \\
\hline \multicolumn{3}{|c|}{ Parameter estimates with two breaks } & \multicolumn{3}{|c|}{ Parameter estimates with two breaks } \\
\hline $\begin{array}{c}\beta_{1} \\
0.0383 * * *\end{array}$ & $\begin{array}{c}\beta_{2} \\
0.0682 * * *\end{array}$ & $\begin{array}{c}\beta_{3} \\
0.0556 * * *\end{array}$ & $\begin{array}{c}\beta_{1} \\
0.0388^{* * *}\end{array}$ & $\begin{array}{c}\beta_{2} \\
0.0720^{* * *}\end{array}$ & $\begin{array}{c}\beta_{3} \\
0.0491 * * *\end{array}$ \\
\hline $\begin{array}{c}\gamma_{1} \\
0.7853^{* * *}\end{array}$ & $\begin{array}{c}\gamma_{2} \\
0.6642^{* * *}\end{array}$ & $\begin{array}{c}\gamma_{3} \\
0.7042^{* * *}\end{array}$ & $\begin{array}{c}\gamma_{1} \\
0.6013^{* * *}\end{array}$ & $\begin{array}{c}\gamma_{2} \\
0.4744 * * *\end{array}$ & $\begin{array}{c}\gamma_{3} \\
0.5570^{* * *}\end{array}$ \\
\hline$c$ & $\alpha$ & & $c$ & $\alpha$ & \\
\hline $2.8300 * * *$ & $0.1652 * * *$ & & $3.3095 * * *$ & $0.2045^{* *}$ & \\
\hline
\end{tabular}

Note: $* * *, * *$ and $*$ denote statistic significant at $1 \%, 5 \%$ and $10 \%$ level respectively. The asymptotic distributions for these tests in BP with trending and non-trending data are fairly similar and Bai and Perron (2003a) suggest that one can safely use the same critical values at the presence of trending data. In brackets are hetroscedasticity and auto-correlation consistent standard errors.

${ }^{a} 1 \%, 5 \%$ and $10 \%$ critical values are $14.92,11.16$ and 9.66 respectively

b $1 \%$ critical value is 16.52

${ }^{\mathrm{c}} 1 \%, 5 \%$ and $10 \%$ critical values are $14.92,10.98$ and 9.37 respectively

${ }^{d} 1 \%, 5 \%$ and $10 \%$ critical values are $16.69,12.55$ and 10.92 respectively

e $1 \%, 5 \%$ and $10 \%$ critical values are $17.41,13.46$ and 11.90 respectively

Critical values are from Bai and Perron (2003c), which is available at Pierre Perron's home page at http://econ.bu.edu/perron/. 
Table 2. Estimates of the CES Production Function

\section{Capital Series $K 1$}

Parameter estimates with two breaks

$\beta_{1}$

0.0428

$\gamma_{1}$

$0.8243^{* * *}$

$c$

4.4244

$\varphi$

0.8002

$$
\beta_{2}
$$

$0.0694 * * *$

$\gamma_{2}$

$0.7195^{* * *}$

$\delta$

0.8453

$\rho$

0.3589

$\delta$

$\rho$ $\beta_{3}$

$0.0609 *$

$\gamma_{3}$

$0.7433^{* * *}$
Capital Series $K 2$

Parameter estimates with two breaks

$\begin{array}{ccc}\beta_{1} & \beta_{2} & \beta_{3} \\ 0.0351 & 0.0621^{* * *} & 0.0439\end{array}$

$\gamma_{1}$

$0.6079 * * *$

$\gamma_{2}$

$0.5094 * * *$

$\gamma_{3}$

$0.5720 * * *$

$c$

$\delta$

$3.9917 \quad 0.7906$

$0.8495 \quad 0.2356$

\begin{tabular}{|c|c|c|c|}
\hline \multicolumn{2}{|c|}{ Wald Test } & \multicolumn{2}{|c|}{ Wald Test } \\
\hline$\varphi=1$ & $\rho=0$ & $\varphi=1$ & $\rho=0$ \\
\hline 0.0263 & 0.0414 & 0.0304 & 0.3318 \\
\hline
\end{tabular}

Wald Test?Chi-square(1)-statistics value is used and probability in brackets.

Table 3. Estimates of the VES Production Function

Capital Series $K 1$

Parameter estimates with two breaks

$\begin{array}{lll}\beta_{1} & \beta_{2} & \beta_{3}\end{array}$

0.0406

$\gamma_{1}$

$0.7999^{*}$

$c$

4.5438

$\varphi$

0.9101
$0.0685^{* * *}$

$\gamma_{2}$

$0.6873^{* * *}$

$\gamma_{3}$

$0.7319 * * *$

$\theta$

0.1850

$\eta$

0.000007
Capital Series $K 2$

Parameter estimates with two breaks $\beta_{1}$

0.0319

$\gamma_{1}$

$0.5888 * * *$

$c$

2.3012

$\varphi$

1.0114 $\beta_{2}$

$0.0620 * *$

$\gamma_{2}$

$0.4757 * * *$

$\theta$

$0.3143^{*}$

$\eta$

0.000002 
Wald Test

$\begin{array}{cc}\varphi=1 & \eta=0 \\ 0.0112 & 0.0378\end{array}$

Note: see note of Table 2 for an explanation
Wald Test

$$
\varphi=1
$$

0.0002

$$
\eta=0
$$

0.7751 
Table 4. Growth Rates of NFP, TFP and CRT and Shares(\%)

\begin{tabular}{|c|c|c|c|c|c|c|}
\hline \multirow[t]{2}{*}{ Year } & \multicolumn{3}{|c|}{$k 1$} & \multicolumn{3}{|c|}{$k 2$} \\
\hline & GTFP1 & GNFP1 & GCRT1 & GTFP2 & GNFP2 & GCRT2 \\
\hline 1980 & n.a. & n.a. & n.a. & n.a. & n.a. & n.a. \\
\hline 1981 & 1.79 & 0.18 & 1.61 & 1.14 & -0.09 & 1.23 \\
\hline 1982 & 5.10 & 5.17 & -0.07 & 4.34 & 4.39 & -0.05 \\
\hline 1983 & 7.40 & 4.86 & 2.53 & 6.65 & 4.71 & 1.94 \\
\hline 1984 & 9.96 & 3.02 & 6.93 & 9.06 & 3.75 & 5.31 \\
\hline 1985 & 8.34 & 4.87 & 3.48 & 7.73 & 5.06 & 2.66 \\
\hline 1986 & 4.68 & 1.66 & 3.02 & 4.07 & 1.76 & 2.31 \\
\hline 1987 & 7.07 & 5.17 & 1.90 & 6.45 & 4.99 & 1.46 \\
\hline 1988 & 6.53 & 5.29 & 1.23 & 6.24 & 5.30 & 0.95 \\
\hline 1989 & 0.66 & 2.01 & -1.36 & 1.49 & 2.53 & -1.04 \\
\hline 1990 & n.a. & n.a. & n.a. & n.a. & n.a. & n.a. \\
\hline 1991 & 6.51 & 5.84 & 0.66 & 6.53 & 6.05 & 0.47 \\
\hline 1992 & 10.90 & 8.95 & 1.95 & 10.59 & 9.20 & 1.39 \\
\hline 1993 & 10.26 & 6.99 & 3.28 & 9.97 & 7.63 & 2.34 \\
\hline 1994 & 9.54 & 6.42 & 3.13 & 9.00 & 6.77 & 2.23 \\
\hline 1995 & 7.64 & 4.66 & 2.98 & 7.13 & 5.00 & 2.13 \\
\hline 1996 & n.a. & n.a. & n.a. & n.a. & n.a. & n.a. \\
\hline 1997 & 6.21 & 5.36 & 0.85 & 5.63 & 4.96 & 0.67 \\
\hline 1998 & 5.01 & 4.87 & 0.14 & 4.41 & 4.30 & 0.11 \\
\hline 1999 & 4.95 & 5.38 & -0.42 & 4.43 & 4.77 & -0.33 \\
\hline 2000 & 5.88 & 5.74 & 0.14 & 5.27 & 5.16 & 0.11 \\
\hline 2001 & 5.48 & 5.48 & 0.00 & 4.87 & 4.87 & 0.00 \\
\hline
\end{tabular}




\begin{tabular}{|c|c|c|c|c|c|c|}
\hline 2002 & 6.48 & 6.48 & 0.00 & 5.69 & 5.69 & 0.00 \\
\hline 2003 & 7.18 & 5.93 & 1.26 & 6.18 & 5.19 & 0.99 \\
\hline 2004 & 7.14 & 4.17 & 2.98 & 6.09 & 3.73 & 2.36 \\
\hline 2005 & 7.68 & 4.95 & 2.73 & 6.38 & 4.22 & 2.16 \\
\hline 2006 & 8.85 & 6.12 & 2.73 & 7.59 & 5.43 & 2.16 \\
\hline 2007 & 10.05 & 7.90 & 2.15 & 8.90 & 7.20 & 1.70 \\
\hline 2008 & 6.51 & 5.00 & 1.50 & 5.48 & 4.29 & 1.19 \\
\hline 2009 & 6.39 & 3.51 & 2.88 & 5.06 & 2.78 & 2.28 \\
\hline 2010 & 7.66 & 6.10 & 1.56 & 6.55 & 5.32 & 1.23 \\
\hline \multicolumn{7}{|c|}{ Mean rates in three regimes } \\
\hline 1980-1989 & 5.72 & 3.58 & 2.14 & 5.24 & 3.60 & 1.64 \\
\hline 1990-1995 & 8.97 & 6.57 & 2.40 & 8.65 & 6.93 & 1.71 \\
\hline 1996-2010 & 6.82 & 5.50 & 1.32 & 5.89 & 4.85 & 1.05 \\
\hline \multicolumn{7}{|c|}{ Shares of GTFP contributed by GNFP and GCRT } \\
\hline $1980-1989$ & & 62.6 & 37.4 & & 68.7 & 31.3 \\
\hline 1990-1995 & & 73.2 & 26.8 & & 80.2 & 19.8 \\
\hline 1996-2010 & & 80.6 & 19.4 & & 82.3 & 17.7 \\
\hline
\end{tabular}

Note: GNFP: growth rate of net factor productivity (technical progress); GTFP: growth rate of total factor productivity; GCRT: growth rate of contribution of rural transformation to total factor productivity; 1 and 2 indicate they are obtained using capital series 1 or 2 respectively. 
Table 5. Comparison with Previous Studies: Capital Share (\%)

\begin{tabular}{|c|c|c|c|}
\hline \multirow{2}{*}{ Sources } & \multirow{2}{*}{ Periods } & \multicolumn{2}{|c|}{ Capital Share (\%) } \\
\hline & & Pre-reform & Post-reform \\
\hline \multirow{3}{*}{ This Study } & & \multicolumn{2}{|c|}{$k 1: 0.1652$} \\
\hline & $1980-2010$ & & \\
\hline & & \multicolumn{2}{|c|}{$k 2: 0.2045$} \\
\hline Chow (1993) & $1952-1988$ & \multicolumn{2}{|c|}{0.6317} \\
\hline Chow and Li (2002) & 1952-1998 & \multicolumn{2}{|c|}{0.5577} \\
\hline Borensztein and Ostry (1996) & 1953-1994 & \multicolumn{2}{|c|}{ n.a. } \\
\hline World Bank (1996) & 1985-1994 & \multicolumn{2}{|c|}{0.5} \\
\hline Hu and Khan (1997) & 1953-1994 & 0.614 & 0.547 \\
\hline Maddison (1998) & 1952-1995 & \multicolumn{2}{|c|}{0.3} \\
\hline Woo (1998) & 1979-1993 & & $0.4,0,5$ and 0.6 \\
\hline Bosworth and Collins (2008) & 1978-2004 & & 0.4 \\
\hline Brandt et al (2008) & 1978-2004 & & 0.5 \\
\hline
\end{tabular}

Table 6. Comparison with Previous Studies: Productivity Growth Rates (\%)

\section{Sources Periods Average Growth Rate (\%)}

\begin{tabular}{|c|c|c|c|c|c|}
\hline & & \multicolumn{2}{|c|}{$k 1$} & \multicolumn{2}{|c|}{$k 2$} \\
\hline & & Regime 1 & GNFP1: 3.58 & Regime 1 & GNFP2: 3.60 \\
\hline & & \multicolumn{2}{|c|}{ GTFP1:5.72 } & \multicolumn{2}{|c|}{ GTFP2:5.24 } \\
\hline & & (1980-1989) & GCRT1: 2.14 & (1980-1989) & GCRT2: 1.64 \\
\hline \multirow[t]{7}{*}{ This Study } & $1980-2010$ & Regime 2 & GNFP1: 6.57 & Regime 2 & GNFP2: 6.93 \\
\hline & & \multicolumn{2}{|c|}{ GTFP1: 8.97} & \multicolumn{2}{|c|}{ GTFP2: 8.65} \\
\hline & & (1990-1995) & GCRT1: 2.40 & (1990-1995) & GCRT2: 1.71 \\
\hline & & Regime 3 & GNFP1: 5.50 & Regime 3 & GNFP2: 4.85 \\
\hline & & \multicolumn{2}{|c|}{ GTFP1: 6.82} & \multicolumn{2}{|c|}{ GTFP2: 5.89} \\
\hline & & (1996-2010) & GCRT1: 1.32 & (1996-2010) & GCRT2: 1.05 \\
\hline & & \multicolumn{2}{|c|}{ Pre-reform (\%) } & \multicolumn{2}{|c|}{ Post-reform (\%) } \\
\hline
\end{tabular}




\begin{tabular}{|c|c|c|c|c|}
\hline \multirow[b]{2}{*}{ Chow (1993) } & \multirow[b]{2}{*}{$1952-1988$} & & \multirow{2}{*}{\multicolumn{2}{|c|}{ n.a. }} \\
\hline & & 0 & & \\
\hline Chow and Li (2002) & $1952-1998$ & 0 & \multicolumn{2}{|l|}{3} \\
\hline $\begin{array}{c}\text { Borensztein and } \\
\text { Ostry (1996) }\end{array}$ & 1953-1994 & -0.7 & \multicolumn{2}{|l|}{3.8} \\
\hline World Bank (1996) & 1985-1994 & & GTFP: 3.6 & GCRT: 1.00 \\
\hline Hu and Khan (1997) & 1953-1994 & 1.1 & \multicolumn{2}{|l|}{3.9} \\
\hline Maddison (1998) & 1952-1995 & -0.78 & \multicolumn{2}{|l|}{2.23} \\
\hline Woo (1998) & 1979-1993 & & $\begin{array}{r}\text { GNFP: } 1.1 \text { to } \\
\text { GCRT: } 1.1\end{array}$ & \\
\hline $\begin{array}{l}\text { Bosworth and Collins } \\
\qquad(2008)\end{array}$ & $1978-2004$ & & GTFP: 6.4 (1978-1993) & GCRT: 1.7 \\
\hline Brandt et al (2008) & 1978-2004 & & GTFP: 6.96 & GCRT: 1.02 \\
\hline
\end{tabular}


Figure 1. Growth rates of TFP

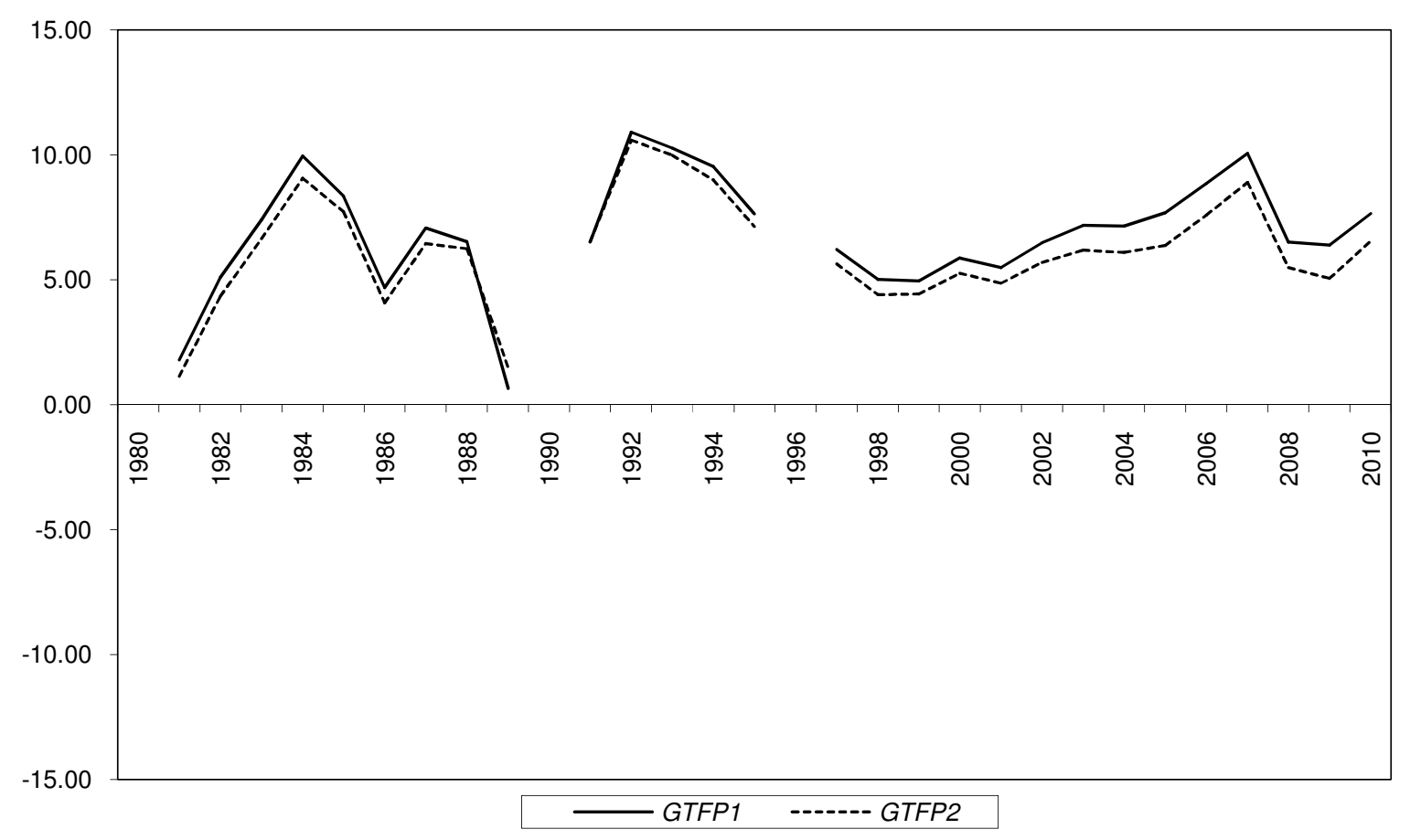

Figure 2. Growth rates of NFP 


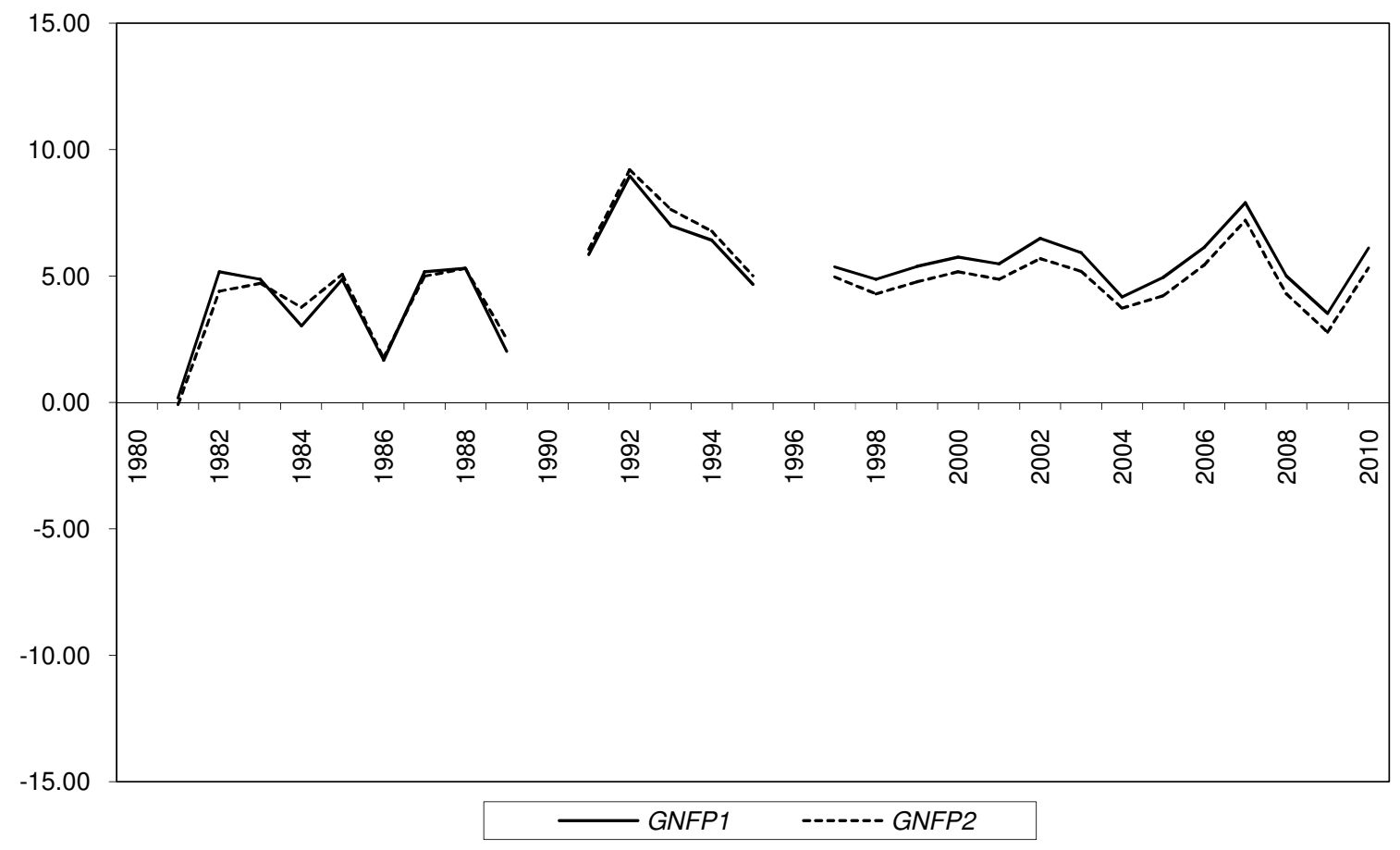

Figure 3. Growth rates of $C R T$ 


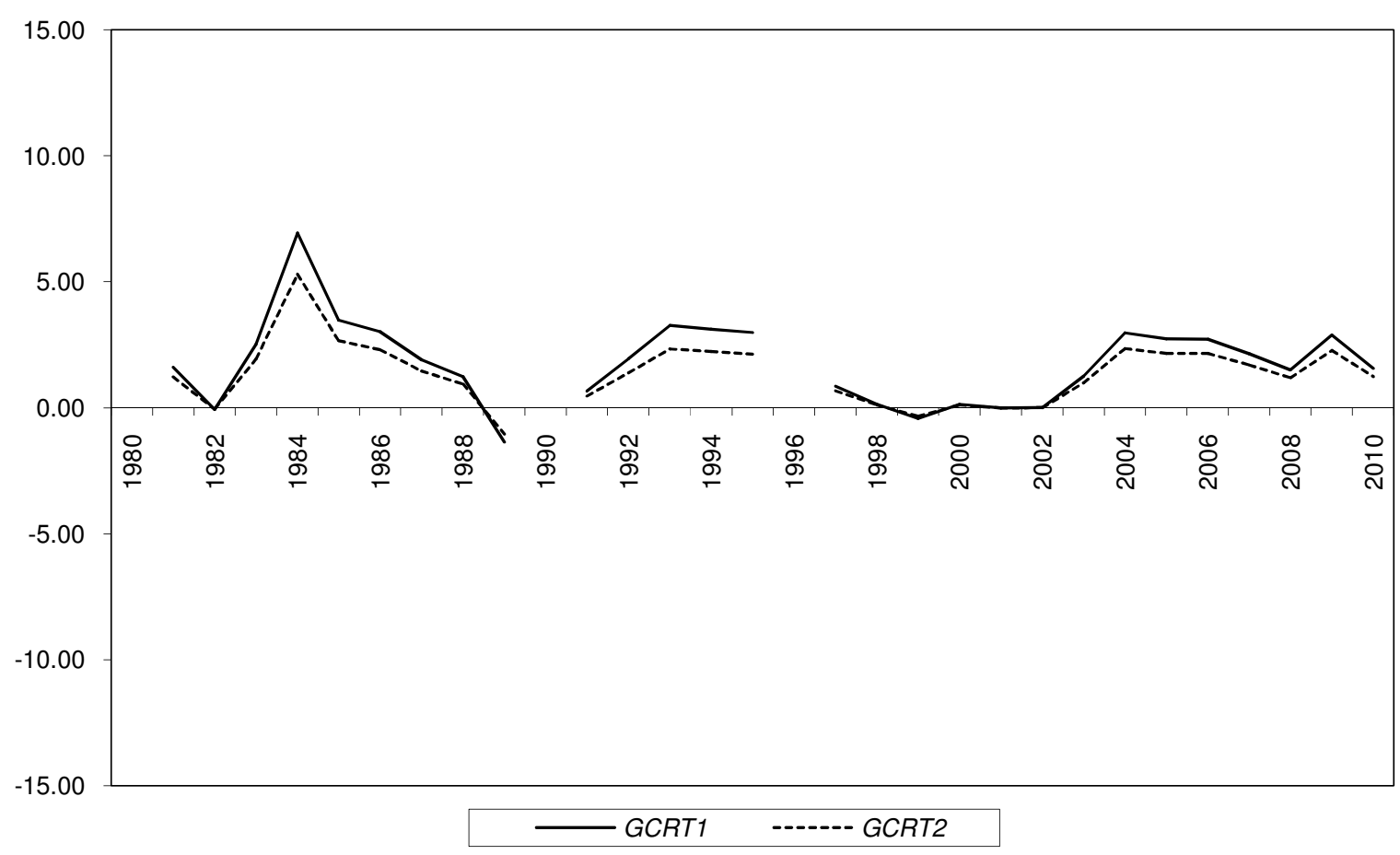

